\title{
El impulso de la incorporación de cláusulas sociales y ambientales en los contratos de la Comunidad Autónoma de Andalucía
}

En el Boletín Oficial de la Junta de Andalucía núm. 230, de 21 de octubre, se publica el Acuerdo de 18 de octubre de 2016, del Consejo de Gobierno, por el que se impulsa la incorporación de cláusulas sociales y ambientales en los contratos de la Comunidad Autónoma de Andalucía.

La importancia que viene adquiriendo la funcionalización de la contratación pública hacia la satisfacción de otros fines de interés público justifica esta breve reseña del Acuerdo².

\section{EL PREÁMBULO DEL AGUERDO DE 18 DE OGTUBRE DE 2016}

En esta ocasión, el preámbulo del Acuerdo no hace glosa y loa de la trayectoria seguida por la Comunidad Autónoma en la materia, a diferencia de lo que suele suceder en otros documentos, actos y disposiciones de la Junta de Andalucía. Y el caso es que existen precedentes de atención a la contratación pública social y ecológica; así, la Ley 1/1999, de 31 de marzo, de atención a las personas con discapacidad en Andalucía; la Ley 18/2003, de 29 de diciembre, por la que se aprueban medidas fiscales y administrativas; la Guía para la contratación pública responsable en Andalucía. Inserción de criterios éticos, sociales y ambientales en la contratación administrativa, de 2006; la Ley 12/2007, de 26 de noviembre, para la promoción de la igualdad de género en Andalucía; el De-

Esta sección ha sido elaborada por MARÍA DEL CARMEN NÚÑEZ LOZANO.

Muestra de ello es la Resolución del Defensor del Pueblo Andaluz, "de posicionamiento sobre la inclusión de cláusulas sociales en la contratación administrativa", formulada en la queja 16/1087, dirigida a Ayuntamientos de Andalucía, Diputaciones Provinciales de Andalucía. No es pertinente en este momento analizar ni valorar los términos de la Resolución, pero valga la referencia como indicación del interés que despierta la materia. 
creto 39/2011, de 22 de febrero, por el que se establece la organización administrativa para la gestión de la contratación de la Administración de la Junta de Andalucía y sus entidades instrumentales y se regula el régimen de bienes y servicios homologados; Cláusulas sociales: dossier para la contratación pública sostenible, de 2011; o Incorporación de cláusulas de igualdad en contratos, subvenciones y convenios públicos, de 2013.

Desconocemos si existe alguna razón en particular para haber prescindido de la reseña de los precedentes andaluces. En todo caso, la memoria histórica del preámbulo del Acuerdo es corta, ya que considera que "[1]a previsión de mecanismos que permiten introducir en la contratación pública cláusulas de tipo social y ambiental, configurándolas como condiciones especiales de ejecución del contrato o como criterios para valorar las ofertas, fue incorporada a nuestro Ordenamiento Jurídico por la derogada ley 30/2007, de 30 de octubre, de Contratos del Sector Público [...]”. Sin embargo, contamos con otros antecedentes más alejados en el tiempo, tanto en el ámbito específico de la contratación pública como en otros sectores normativos.

Así, pueden citarse en el ámbito estatal, entre otros, el artículo 24.3 de la Ley 48/1998, de 30 de diciembre, sobre procedimientos de contratación en los sectores del agua, la energía, los transportes y las telecomunicaciones, por la que se incorporan al ordenamiento jurídico español las Directivas 93/38/CEE y 92/13/ $\mathrm{CEE}^{3}$; el primer párrafo de la disposición adicional $3^{\mathrm{a}}$ de la Ley 11/1997, de 24 de abril, de Envases y Residuos de Envases ${ }^{4}$; o el artículo 26.2 de Ley 10/1998, de 21 de abril, de Residuos 5 . También puede citarse, aun teniendo en cuenta su limitado ámbito de aplicación y su caracterización como instrucción u orden de servicio, la Orden MAM/2116/2007, de 10 de julio, sobre requisitos y criterios medioambientales a introducir en los pliegos de cláusulas administrativas que rijan en los contratos del Ministerio de Medio Ambiente y los Organismos Públicos de él dependientes; esta Orden, anterior también a la Ley 30/2007, vino a sustituir a la Orden Ministerial de 14 de octubre de 1997 que, con imperfecciones técnicas, fijó los criterios de modificación de los pliegos de cláusulas administrativas particulares que había de regir la contratación en el Ministerio de Medio Ambiente para incluir la valoración ambiental como exigencia objetiva de resolución de los concursos que se convocasen.

\footnotetext{
"En el concurso, la adjudicación recaerá sobre el licitador que, en su conjunto, haga la proposición más ventajosa. Este extremo se determinará de acuerdo con diversos criterios objetivos variables según el contrato en cuestión, tales como [...] calidad ambiental [...]".

4 "Las Administraciones públicas adoptarán las medidas necesarias para favorecer el orden de prioridades indicado en el segundo párrafo del apartado 1 del artículo 1 y promoverán el uso de materiales reutilizables y reciclables en la contratación de obras públicas y suministros".

5 "Las Administraciones públicas promoverán el uso de materiales reutilizables, reciclables y valorizables, así como de productos fabricados con material reciclado que cumplan las especificaciones técnicas requeridas, en el marco de la contratación pública de obras y suministros".
} 
Aun cuando en el preámbulo del Acuerdo no se menciona nada, interesa reseñar que ha venido precedido a su vez de un acuerdo sobre la materia entre la Consejería de Hacienda y Administración Pública, los sindicatos UGT y CCOO y la Confederación de Empresarios de Andalucía. Con ocasión de su firma, que tuvo lugar el 10 de octubre de 2016, desde la Junta de Andalucía se ha destacado su "carácter pionero" y la confianza en que "sirva de ejemplo" para el resto de administraciones 6 . Sin embargo, lo cierto es que las iniciativas de este tipo han venido proliferando en otras administraciones públicas - estatal, autonómicas y locales- desde hace ya tiempo, algunas de ellas al más alto nivel, como es el caso de la Ley 3/2016, de 7 de abril, de la Comunidad Autónoma del País Vasco, para la inclusión de determinadas cláusulas sociales en la contratación pública.

El Acuerdo que examinamos invoca el artículo 47.2.3 del Estatuto de Autonomía para Andalucía como título competencial que lo ampara; dicho precepto atribuye a la Comunidad Autónoma la competencia compartida en materia de contratos y concesiones administrativas ${ }^{7}$. También menciona el Texto Refundido de la Ley de Contratos del Sector Público, aprobado por el Real Decreto Legislativo 3/2011, de 14 de noviembre, así como "las nuevas Directivas sobre contratación, aprobadas por el Parlamento Europeo el 15 de enero de 2014 y publicadas en DOUE el día 28 de marzo", aunque después, en su parte dispositiva, solo cita expresamente la Directiva 2014/24/UE.

Por último, el preámbulo del Acuerdo intenta poner en valor esta iniciativa del Gobierno andaluz con un párrafo final de grandes frases ${ }^{8}$, algunas vacías de conte-

${ }^{6}$ http://www.juntadeandalucia.es/presidencia/portavoz/gobierno/115491/susana/diaz/ destaca/clausulas/sociales/protegeran/derechos/trabajadores/empresas/contratan/administracion

Ya el artículo 15.1.2 del Estatuto aprobado por la Ley Orgánica 6/1981, de 30 de diciembre, había contemplado la competencia de la Comunidad sobre desarrollo legislativo y ejecución de contratos y concesiones administrativas, en el marco de la regulación general del Estado. En estos 35 años de andadura autonómica no ha habido ocasión para que el Parlamento apruebe una ley autonómica en la materia, de manera que sólo contamos con una serie de normas dispersas y de diferente rango que disciplinan aspectos variados de la contratación pública.

8 "La existencia de una política de compra social y ambientalmente sostenible constituye una base adecuada sobre la que construir un enfoque coherente y coordinado. En este marco, y teniendo en cuenta que este Gobierno entiende que toda actuación del sector público ha de estar encaminada al servicio del bienestar colectivo y a la consecución de los intereses sociales, la Junta de Andalucía hace una fuerte apuesta para que sus actividades de contratación y compra jueguen un papel ejemplar en la protección del medio ambiente, las políticas sociales y el fomento de la innovación, todo ello en un ánimo integrador, en el cual, de una forma eficaz, queden debidamente conciliados los objetivos y principios inherentes a la contratación pública, principalmente los relativos al empleo -calidad y mantenimiento-, los derechos de las personas trabajadoras y la calidad en la prestación de los servicios públicos, con otros, que sin ser ajenos en sentido estricto a este ámbito, se refieren al desarrollo de políticas de sostenibilidad de empleo e inserción social, de medioambiente y de igualdad de género". 
nido $^{9}$ y otras inexactas ${ }^{10}$. Quizás por eso se haya prescindido de la mención de los precedentes andaluces, para realzar así el significado del Acuerdo.

\section{EL CONTENIDO DEL ACUERDO DE 18 DE OGTUBRE DE 2016}

El Acuerdo está compuesto por trece apartados, de los cuales seis se dedican específicamente a aspectos concretos de los contratos y uno a los contratos reservados. Se reseñan a continuación todos ellos con la brevedad que requiere las características de esta sección de la Revista.

El primer apartado se refiere al objeto del propio Acuerdo: "la incorporación de cláusulas sociales y ambientales en los contratos que celebre la Administración de la Junta de Andalucía y sus entes instrumentales". Tras precisar los fines que se pretenden $^{11}$, se señala que las licitaciones de la Junta de Andalucía "incluirán estipulaciones tendentes a lograr objetivos de política social, ética y ambiental, en su versión más amplia ${ }^{12 "}$ y ello "siempre que dichos aspectos se puedan incorporar al objeto del contrato, sean compatibles con el derecho comunitario ${ }^{13}$, y se indique en el anuncio de licitación y en los pliegos del contrato". El apartado contiene una enumeración de los objetivos sociales y ambientales, que debe entenderse incorporada a título ejemplificativo: "oportunidades de empleo, trabajo digno, cumplimiento de los derechos sociales y laborales establecidos en la normativa y en los convenios colectivos, inclusión social, incluidas las personas con discapacidad, igualdad de oportunidades, accesibilidad universal y diseño para todas las personas, consideración de los criterios de sostenibilidad,

9 Por ejemplo: "La existencia de una política de compra social y ambientalmente sostenible constituye una base adecuada sobre la que construir un enfoque coherente y coordinado".

10 Se alude al fomento de la innovación, cuando lo cierto es que el Acuerdo, inoportunamente a nuestro juicio, solo la potencia de modo indirecto, a través de la denominada contratación ecológica. También se indica que la calidad y el mantenimiento del empleo, así como los derechos de las personas trabajadoras, son objetivos y principios inherentes a la contratación pública, lo que a todas luces es un exceso: una cosa es que sea deseable que la contratación pública contribuya a la calidad y al mantenimiento del empleo, así como que los derechos de los trabajadores deban ser respetados, y otra muy diferente el que estas cuestiones sean "objetivos y principios inherentes" a ella.

11 " [...] contribuir a la promoción y consolidación de un tejido empresarial sostenible, la apuesta por un empleo de calidad, con un fuerte compromiso social y ambiental así como a la consecución de un sistema de contratación pública sostenible, que aúne política social, balance social y redistribución equilibrada de la riqueza, profundizando en las raíces de un Estado del bienestar que promueva la igualdad de oportunidades, pensando en el propio bienestar de generaciones venideras".

12 Llama la atención esta referencia específica a los objetivos de política ética, que mencionados junto a los de política social y ambiental parecen ser algo distinto de estos. Aunque en no pocas ocasiones se alude a los objetivos de política social como objetivos éticos de la contratación, la mención "ética" a continuación de la mención "social" sugiere, como se acaba de decir, un añadido diferente.

13 En nuestra opinión, hubiera sido más correcta la referencia al Derecho de la Unión Europea. 
incluidas las cuestiones de comercio ético y cumplimiento voluntario más amplio de la responsabilidad social de las empresas, respeto al medio ambiente y al ciclo de la vida, estímulo de los mercados de los productos con ventajas ambientales, para reducir los efectos adversos sobre la salud humana, así como para reducir el uso de la energía, las emisiones toxicas o el agotamiento de los recursos naturales".

El segundo apartado ("ámbito subjetivo y principios") reitera que el Acuerdo es aplicable a los "contratos de la Administración de la Junta de Andalucía y sus entidades instrumentales públicas" y dispone que "es de aplicación preceptiva para todos sus órganos de contratación". Sobre este particular, debemos llamar la atención sobre la inexactitud de su título, que se refiere a los contratos de la Comunidad Autónoma de Andalucía, siendo así que, como resulta obvio, la Administración de la Junta de Andalucía no es la Comunidad Autónoma.

Para facilitar que los órganos de contratación incorporen este tipo de cláusulas a los documentos contractuales, el apartado tercero prevé la aprobación de una guía sobre la materia, como seguidamente veremos. En todo caso, la efectiva aplicación del Acuerdo no requiere, en principio, la aprobación de ninguna norma específica, ya que los objetivos que a título de ejemplo considera su apartado primero son lo suficientemente genéricos como para poder ser alcanzados, en una u otra medida, con la aplicación del marco jurídico vigente. No obstante, el apartado undécimo desvela el propósito de introducir en el Ordenamiento jurídico determinadas exigencias encaminadas a garantizar el cumplimiento de los convenios colectivos y la subrogación del personal en los cambios de titularidad de las contratas, para lo que el Acuerdo sí considera necesaria una previa modificación del Ordenamiento jurídico. Dado que no se concretan cuáles son estas exigencias, no resulta posible valorar a priori en qué medida es necesaria o no la reforma normativa que se anuncia.

En todo caso, hay que tener en cuenta que una cosa es que la Administración de la Junta de Andalucía decida obligarse a sí misma mediante un Acuerdo de este tipo, de eficacia interna o doméstica; y otra muy diferente que a través de una norma jurídica se concrete el nivel de compromiso social y ambiental que se asume, de modo que se pueda demandar su cumplimiento y pretender, si llegara el caso, la invalidez de las licitaciones que no se ajusten al mismo.

El apartado primero enumera también una serie de principios para precisar que el Acuerdo debe aplicarse sin menoscabo de los mismos o con respeto a ellos, lo que parece innecesario habida cuenta cuáles son en concreto los que enumera: los de "eficacia y eficiencia que rigen la ejecución del gasto público" y "los principios generales que rigen la contratación pública y, en particular, los de libre circulación de mercancías y libre prestación de servicios, publicidad, concurrencia, igualdad y no discriminación, transparencia y proporcionalidad". 
En el tercer apartado, como ya se ha anticipado, se insta a la Consejería con competencia en materia de Hacienda a la aprobación de una guía sobre la materia. Su finalidad es la de "facilitar a los órganos de contratación la incorporación de estas cláusulas en los distintos documentos contractuales" y también la de "establecer cláusulas de obligado cumplimiento para todos los órganos de contratación, así como cláusulas recomendadas que éstos podrán adaptar o modular en cuanto a su redacción conforme a las características de cada contrato". Se trata de una medida que cuenta ya con precedentes, tanto en Andalucía, como se indicó anteriormente, como en el ámbito de otras administraciones públicas; también viene siendo frecuente que otras organizaciones del tercer sector publiquen guías de este tipo. A la fecha en que se escribe esta reseña no tenemos datos sobre la efectiva aprobación de la guía, aunque sí existe un borrador de octubre de 2016 que ha difundido la Administración de la Junta $^{14}$. Del contenido del borrador se desprende que la guía podría aprobarse con naturaleza normativa, pues se distingue entre cláusulas obligatorias y recomendaciones de carácter general ${ }^{15}$. No cabe duda de que, si así fuera finalmente, efectivamente se produciría un avance significativo en lo que concierne especialmente a las cláusulas ambientales, pues hasta la fecha se ha dedicado mayor atención a las denominadas cláusulas sociales.

El cuarto apartado, primero de los que se refieren específicamente al contrato, trata de su objeto. La definición del mismo "hará referencia de forma clara al valor social y ambiental de los productos, servicios y obras que se necesite contratar, en razón a sus características concretas en los términos establecidos en la Guía". Se añade que "cuando la perspectiva de género o los valores sociales y ambientales constituyan una característica destacable del objeto del contrato, se incluirá expresamente en su definición”. Esta última mención es reiterativa respecto de la primera, salvo en lo que concierne a la perspectiva de género.

El quinto apartado recoge los criterios con arreglo a los cuáles deben definirse las prescripciones técnicas cuando el objeto del contrato sea apropiado para ello. Estos criterios son los de índole social, de sostenibilidad y protección ambiental y, también, de accesibilidad universal y de diseño para todas las personas. Los primeros han de tener por finalidad "promocionar intereses generales de la sociedad, relacionados con

\footnotetext{
14 http://www.juntadeandalucia.es/presidencia/portavoz/resources/ files/2016/10/10/1476176823144guiaOK.pdf

15 En la p. 22 de la Guía se indica lo siguiente: "En esta guía se incorporan dos tipos de cláusulas, unas serán de obligatoria inclusión en los pliegos de cláusulas administrativas particulares según lo establecido en la norma que apruebe la presente guía y otras son recomendaciones establecidas con carácter general, con el fin de facilitar la toma de decisiones a los órganos de contratación a la hora de incluir las mismas en los correspondientes documentos del expediente de contratación" (la negrilla en el original y la cursiva añadida).
} 
el empleo de calidad, la inclusión social, la promoción de la igualdad de género, la economía social, la integración laboral o, en definitiva, la promoción de valores relacionados con la mejora de las condiciones de trabajo de las personas trabajadoras, y en especial, aquellas en circunstancias más vulnerables". Los segundos "pueden referirse, entre otros, a niveles de cumplimiento ambiental, uso de productos determinados, procesos de producción, características ambientales de producto". Respecto a los criterios de accesibilidad universal y de diseño para todas las personas, el Acuerdo se remite a la definición de los mismos en la Ley 51/2003, de 2 de diciembre, de igualdad de oportunidades, no discriminación y accesibilidad universal de las personas con discapacidad.

El sexto apartado, sobre la solvencia técnica, establece que "[1]a exigencia de capacidad técnica social o ambiental se realizará en condiciones de transparencia indicando en el Pliego de cláusulas administrativas particulares los criterios objetivos que se utilizarán para la admisión, así como el nivel de capacidades específicas requeridas".

El séptimo apartado aborda los criterios de adjudicación precisando que "[s]e introducirán criterios sociales y ambientales entre los criterios de adjudicación, siempre que estén vinculados al objeto del contrato, sean proporcionales al mismo y figuren expresamente determinados en el anuncio y en el pliego, en aplicación de los principios de transparencia e igualdad de trato que deben regir la contratación pública". A continuación, se aclara que "se considerará que un criterio de adjudicación está vinculado al objeto del contrato cuando se refiera o integre las prestaciones que deban realizarse en virtud de dicho contrato en cualquiera de sus aspectos y en cualquier etapa de su ciclo de vida, de acuerdo con lo establecido en los artículos 67 y 68 de la Directiva 2014/24/UE del Parlamento europeo y del Consejo"16.

El apartado octavo da entrada a los criterios sociales y ambientales como criterios de desempate. Así, "[c]uando varias proposiciones sean las más ventajosas una vez aplicado los criterios que sirvan de base para la adjudicación, se aplicarán preferentemente criterios de desempate que tendrán en cuenta consideraciones sociales y ambientales, que serán indicados en los pliegos". En nuestra opinión, mejor hubiera sido expresar que se aplicarán preferentemente criterios de desempate que tengan en cuenta las consideraciones sociales y ambientales.

16 Puestos a citar el Derecho derivado de la Unión Europea, se debería haber hecho referencia también al artículo 41 de la Directiva 2014/23/UE del Parlamento Europeo y del Consejo, de 26 de febrero de 2014, relativa a la adjudicación de contratos de concesión; y a los artículos 82 y 83 de la Directiva 2014/25/UE del Parlamento Europeo y del Consejo, de 26 de febrero de 2014, relativa a la contratación por entidades que operan en los sectores del agua, la energía, los transportes y los servicios postales y por la que se deroga la Directiva 2004/17/CE. 
El apartado noveno trata de las condiciones especiales de ejecución de carácter social o ambiental, que tienen que ser "adecuadas a la naturaleza de la prestación contratada y se deben referir a obligaciones a cumplir por la persona adjudicataria durante la ejecución del contrato". Añade, más en clave de "guía" que de "acuerdo", que "[e]s recomendable atribuir el carácter de obligaciones contractuales esenciales a las condiciones especiales de ejecución de carácter social o ambiental al objeto de considerar su incumplimiento como causa de resolución del contrato, independientemente de que se establezcan penalidades". Asimismo, precisa que "[1]as condiciones especiales de ejecución de carácter social o ambiental podrán ser compatibles con los criterios de adjudicación de carácter social o ambiental”.

El último de los apartados referidos a los contratos, el décimo, sobre los contratos reservados, anticipa que "mediante Orden de la Consejería con competencia en materia de Hacienda se determinarán las condiciones para garantizar el cumplimiento de lo establecido en la normativa vigente sobre contratos reservados que deberá ser abordada en el marco del seguimiento y control establecido en la disposición duodécima del presente acuerdo". Recordemos que el artículo 116 de la Ley 18/2003, ya citada, prescribe la reserva de un porcentaje de la adjudicación de contratos de suministros, consultoría y asistencia y de servicios ${ }^{17}$ a centros especiales de empleo y a entidades sin ánimo de lucro inscritas en los correspondientes registros oficiales de la Comunidad Autónoma de Andalucía, siempre que la actividad de dichos centros y entidades tenga relación directa con el objeto del contrato ${ }^{18}$; este porcentaje de reserva debe ser como mínimo del 10 por 100 y como máximo del 20 por 100 del importe total de los contratos de suministros, consultoría y asistencia y de servicios adjudicados en el ejercicio anterior mediante contratos menores o por procedimientos negociados en razón de la cuantía por cada Consejería u Organismo, siempre que existan suficientes ofertas por parte de los centros, entidades y empresas que reúnan las características señaladas en el precepto ${ }^{19}$.

El apartado undécimo versa sobre el impulso de cambios normativos e insta a la Consejería competente en materia de Hacienda a iniciar los trámites legales "que posibiliten el introducir en la normativa correspondiente las cláusulas relativas a ga-

\footnotetext{
17 Exclusivamente los que se adjudiquen como contrato menor o por procedimiento negociado por razón de la cuantía.

$18 \mathrm{Al}$ efecto, deberán tener en su plantilla al menos un 25 por 100 de trabajadores contratados a tiempo completo con un grado de minusvalía igual o superior al 33 por 100. También las empresas que en sus centros de trabajo radicados en Andalucía tengan al menos un 25 por 100 de trabajadores contratados a tiempo completo con un grado de minusvalía igual o superior al 33 por 100 podrán ser adjudicatarias de estos contratos.

19 Aunque no se considerarán para el cálculo del porcentaje de reserva los contratos de suministros de material fungible sanitario y farmacéutico.
} 
rantizar el cumplimiento del convenio colectivo aplicable, así como la subrogación del personal en los cambios de titularidad en la contrata, con el objetivo de velar por el respeto de las condiciones laborales del personal que desarrolla su actividad en las contrataciones realizadas por la Administración de la Junta de Andalucía y facilitar un marco de competencia leal a las empresas que optan a ser adjudicatarias de las contrataciones". El Acuerdo le señala a la Consejería un plazo máximo de dos meses y precisa que se llevará a cabo en el marco de la comisión de seguimiento y control a que se refiere el siguiente apartado.

El apartado duodécimo, en efecto, de ocupa del seguimiento y control, instando a la Consejería con competencia en materia de Hacienda para que inicie los trámites para la constitución de una comisión de seguimiento y control de la aplicación de las cláusulas sociales y ambientales en la contratación pública, que también debe abordar las modificaciones normativas. Esta comisión, en la que han de participar las organizaciones sindicales más representativas de la comunidad autónoma ${ }^{20}$ y las organizaciones empresariales, debía constituirse en el plazo máximo de 1 mes. No tenemos noticias de que ello haya sido así.

Finalmente, el apartado decimotercero determina que el Acuerdo surta efectos desde el siguiente al de su publicación en el Boletín Oficial de la Junta de Andalucía.

\section{VALORACIÓN}

El Acuerdo de 18 de octubre de 2016, como tal y dado que pretende impulsar la utilización de cláusulas sociales y ambientales en la contratación de la Administración de la Junta de Andalucía, sólo puede merecer una valoración muy positiva, y ello tanto desde el punto de vista del valor que entrañan los objetivos sociales y ambientales en sí mismos considerados como desde la perspectiva del uso inteligente de los recursos públicos.

Aunque la utilización del tipo de cláusulas a que se refiere el Acuerdo no puede calificarse en modo alguno como una iniciativa pionera, ni siquiera en el propio nivel de Andalucía, no cabe duda de que puede alcanzar un decisivo impulso tras este Acuerdo. Es de esperar entonces que, por una parte, no se retrase la publicación de la guía aludida; y, por otra parte, que se lleven a cabo las modificaciones normativas anunciadas, de modo que el uso de estas cláusulas, en la medida en que todavía no venga impuesto por el Ordenamiento jurídico, adquiera el carácter de verdadera obligación.

20 "[E]x artículos 6 y 7 de la LOLS" se añade literalmente y entre paréntesis, lo que no parece correcto. 